\title{
ASSESSING THE ZINC CONCENTRATION IN FRUIT AND SEED OF SOME CUCURBITACEAE GROWN IN NIGERIA
}

\author{
Ogbuanu, C.C.* and Eneh, O.C. (Ph.D.) ${ }^{1}$ \\ *Author for correspondence, Department of Industrial Chemistry, Enugu State University of Science and Technology, Agbani-Enugu, \\ Nigeria, Mobile: +234-806-795-8630, \\ Email:cyrilogbuanu@gmail.com \\ ${ }^{1}$ Institute for Development Studies, Enugu Campus, University of Nigeria, Nsukka.
}

DOI: 10.31364/SCIRJ/v7.i1.2019.P0119602

http://dx.doi.org/10.31364/SCIRJ/v7.i1.2019.P0119602

\begin{abstract}
Information-poor countries experience inadequate food supplements, such as zinc due to lack of information and poverty. Zinc content of fruit and seed of Cucurbitaceae family was studied using Atomic Absorption Spectroscopy (AAS). The result showed higher concentrations $(\mathrm{mg} / \mathrm{kg}$ ) of zinc in seeds (pumpkin $82.06 \pm 0.033$, cucumber $65.04 \pm 0.025$, water melon $39.97 \pm 0.016$ and cucumis melon $30.62 \pm 0.020$ ) than in fresh fruits (pumpkin 1.82 \pm 0.027 , cucumber $0.83 \pm 0.017$, water melon $0.47 \pm 0.005$ and cucumis melon $0.40 \pm 0.010$ ). Since the seeds of pumpkin, cucumber, water melon and cucumis melon were very good sources of zinc, the study recommended their increased consumption to help protect against prostate enlargement, maintain a regular sperm count, mobility and regular level of testosterone and activate many enzymes in every organ in the body.
\end{abstract}

Keywords: Cucurbitaceae, Zinc, Seed, Fruit.

\subsection{Introduction}

Zinc is an essential mineral found in trace amounts throughout the body. It is often found in conjunction with protein. It is transported in the blood via the protein albumin.

Zinc is a co-factor used to activate dozens of enzymes in every organ in the body, bone and the prostate gland in men. The eyes have the highest concentration of zinc while about $50 \%$ of the total zinc in the body is found in the muscles.

Zinc is essential in maintenance of normal serum testosterone. Inadequate zinc levels prevent the pituitary gland from releasing eternizing and follicle stimulating hormone which stimulate testosterone production (Sandstead, 1991). Zinc also inhibits the aromatase enzymes that converts testosterone into estrogen. The testosterone to estrogen ratio in men decline with age from as high 50:1 to half of that or even as low as 10:1. Higher estrogen activity results in increased risk of heart disease, weight gain and obesity (Dudkas and Miller, 1999).

One reason for the progressive weight gain with age is that fat cells contain aromatase. More fat cells mean more estrogen which means more fat deposition. This is further aggravated by alcohol consumption which lowers zinc and increase estrogen and so magnifies the problem in addition to the impact on hormone levels. Zinc also has been proven to help the body produce healthier sperm by increasing sperm count and motility. The volume of sperm and testosterone concentration also drops up to $30 \%$ when zinc intake is low (Ahmad et al., 2009)

Zinc deficiency has been found to have a severe impact on the male prostate gland. It predisposes the prostate to infection (prostatic) which may lead to enlargement of the prostate gland (prostatic hypertrophy) (Freeland-Graves and Friedman, 1982). Zinc also plays a role in cell division and DNA replication thereby aiding in the production of immune system cell (Frederickson, 1989).

Zinc gluconate lozenges taken at first sign of a cold reduces duration and symptoms severity (Singh and Das, 2011). Zinc is an antiviral and astringent agent, it is released into the saliva, relieving cough, nasal drainage and congestion (Fosdire, 1990).

The vesicle of the mossy fibers system of the brains hippocampus contains zinc. These play a role in enhancing memory and thinking skills (Chandra, 1984; Vallee and Falchuk, 1990).

In treating rashes, itching and chapped lips and skin, zinc oxide is employed as an astringent (Anderson, 1995). Zinc sulphate in a water-based solution is used in treating acne, cold sores and burns. Zinc stimulate cell division, healing proper connective tissue formation and increase the transportation of vitamin A from the liver to the skin, helping to protect body tissues from damage and repair any damaged one present (Brown and Peerson, 2002).

In reducing fatigue, mood swings and changes in appetite, zinc sulphate taken as a supplement is effective (Sawada, 2010). Pre-menstrual syndrome (PMS), which affects $50 \%$ of all menstruating women, can be managed with zinc. Trace amount of zinc regulates the secretion of many hormones including progesterone. Zinc deficiency underlines PMS (Van Wouwe, 1989). Adequate 
zinc in pregnant mothers' diet reduces the risk of premature birth and other complication and also improves neonatal survival (Simmer, 1985).

This sturdy was tailored towards generating data that will encourage men of age 35 and above to eat more of food that are rich in zinc, so as not develop prostate enlargement and maintain high level of blood testosterone. The data will also help in prescribing diet for pregnant mothers and women of pre-menstrual ages.

\subsection{Material and methods \\ 2.1 Plant materials}

This study was carried out in Industrial Chemistry Department Laboratory of Enugu State University of Science and Technology, Agbani. Plant samples were seeds and fruits of pumpkin, cucumber, water melon and cucumis melon and were bought from Ogbete Main Market, Atisan Market and New Haven Fruit Market all in Enugu municipal. They were confirmed as right by experts in Botany of the University.

\subsection{Sample preparation}

About $3 \mathrm{~g}$ of sample was weighed into a dry crucible and ashed at $500^{\circ} \mathrm{C}$ for 30 minutes in a muffle furnace. The ash obtained was dissolved in $100 \mathrm{ml}$ aqua-regia and the content heated to dryness without baking. The digest was dissolved with glass distilled water and the volume made up to $50 \mathrm{ml}$ with glass distilled water and stored in a clean plastic bottle for analysis.

\subsection{AAS analysis of the sample}

The metal ions present in the sample digest were determined by aspiration with the atomic absorption spectrophotometer. The micro software package coupled to the AAS for representation of data was switched on and the concentration of the trace metal recorded.

\subsection{Results and discussion}

The results of the trace metal analysis carried out on the seeds and fruits of pumpkin, cucumber, water melon and cucumis melon are presented in Table 1. The seeds had higher concentrations $(\mathrm{mg} / \mathrm{kg}$ ) of zinc (pumpkin $82.06 \pm 0.033$, cucumber $65.04 \pm 0.025$, water melon $39.97 \pm 0.016$ and cucumis melon $30.62 \pm 0.020$ ) than the fresh fruits (pumpkin $1.82 \pm 0.027$, cucumber $0.83 \pm 0.017$, water melon $0.47 \pm 0.005$ and cucumis melon $0.40 \pm 0.010$ ).

$\begin{array}{lll}\begin{array}{l}\text { Table 1: Concentration of zinc in the seeds and fruits of Cucurbitaceae family } \\ \text { Sample } \\ \text { Mean and standard deviation conc. } \\ \text { in seeds (mg/kg) }\end{array} & \begin{array}{l}\text { Mean and standard deviation conc. in } \\ \text { fruits }(\mathbf{m g} / \mathbf{k g})\end{array} \\ \text { Pumpkin } & 82.05 \pm 0.033 & 1.82 \pm 0.027 \\ \text { Cucumber } & 65.07 \pm 0.025 & 0.83 \pm 0.017 \\ \text { Water melon } & 39.97 \pm 0.016 & 0.47 \pm 0.005 \\ \text { Cucumis melon } & 30.62 \pm 0.021 & 0.40 \pm 0.010\end{array}$

Standard zinc Normal range in plants (ppm) concentration in plant $\quad 0.100-0.400$

Critical concentration in plants (ppm) $0.500-0.700$

From the result, the range of zinc in seeds are far higher than that in the fruits of the samples studied. This shows that seeds are a better source of zinc than the fruits.

However, the zinc concentration in pumpkin samples were found to be $82.05 \pm 0.033$ in the seeds and $1.82 \pm 0.027$ in the fruits respectively, while cucumber is $65.07 \pm 0.025$ in seeds and $0.83 \pm 0.017$ in fruits. This shows that the zinc concentration in seeds and fruits of pumpkin and water melon are far higher than the normal and critical concentration in plants. Prolonged excessive dietary intake of zinc rich food can lead to deficiencies in iron and copper, nausea, vomiting, fever, headache, tiredness, and abdominal pain In humans (more than $200 \mathrm{mg} /$ day of zinc) (Expert Group on Vitamins and Minerals, 2003; National Institutes of Health, 2013; British National Formulary).

The result also revealed that water melon and cucumis melon has concentration of $39.97 \pm 0.016$ and $30.62 \pm 0.021$ respectively in seeds and far higher than the normal and critical concentration in plants. On the other hand, zinc concentration in fruits of water melon and cucumis melon $(0.47 \pm 0.005$ and $0.40 \pm 0.010)$ were above the normal range in plants and below the critical concentration in plants.

This research have shown Cucurbitaceae family of plants as rich and good source of zinc. Its regular consumption will help to protect prostate gland against infections and enlargement. It will also help in maintaining a regular sperm count, mobility and regular level of testosterone in men. Again, zinc acids will help a lot in treating symphonines associated with premenstrual syndromes in women. Therefore it can be recommended that people of age 45 years and above should increase consumption of Cucurbitaceae family. 
People who do not eat meat (Vegetarians), which is a good source of zinc. Also, the beans and grains they typically eat have compounds that mask zinc from being fully absorbed by the body Because alcoholic beverages decrease the amount of zinc that the body absorbs and increase the amount lost in the urine (NIH, 2016). For this reason, vegetarians and alcoholics might need to eat more of Cucurbitaceae family seeds and fruits to make up the shortfalls.

\section{References}

Ahmad, H., Mark, G., Steven, C.H., Ted, D.A., Douglass, T.C., Ronette, L.K. and Meikle, A.W. (2009). Effect of Roux-on-Y Gastric Bypass Surgery on the sex steroids and quality of life in Obese Men. J. Clin. Endocrinol Metab, 94(4): 1329-1332.

Anderson, I. (1995). Zinc as an aid to healing. Nurs Times, 91(68): 70

British National Formulary.

Chandra, R.K. (1984). Excessive Intake of zinc impairs immune responses. JAMA, 252:1443-1446.

Dudka, S. and Miller, W.P.J. (1999). Determination and consequences of obesity. Envir. Sc. and Health Technol., 34:681-708.

Expert Group on Vitamins and Minerals, (2013). Risk Assessment - Zinc

Fosmire, G.J. (1990). Zinc Toxicity. Am J. Cin. Nutr., 51: 225-227.

Fredrickson, C.J. (1989). Neurobiology of zinc and zinc containing neurons. Int. Rev. NEUROBIOL, 31:145-238.

Freeland-Graves, J.H., Friedman, B.J., Han, W.H., Shorey, R.L. and Young, R. (1982). Effect of zinc supplementation on plasma high-density liproprotein cholesterol and zinc. Am. J. Clin. Nutr., 35: 988-992.

N I H. (2013). Zinc - Fact Sheet for Health Professional. Office of Dietary Supplements, National Institutes of Health

N I H. (2016). What is zinc and what does it do? Office of Dietary Supplements, National Institutes of Health

Sandstead, H.H. (1991). Zinc deficiency: A public Health problem? Am. J. of Disease of Childhood, 145(8): 853-859.

Sawada, T. (2010). Effect of zinc supplementation on mood states in young women: A pilot study. Euro. J. of Clin. Nutr., 64: 331333.

Simmer,K. and Thompson, R.P. (1985). Zinc in the fetus and newborn. Acta. Paediatr Scand Suppl., 319: 158-163.

Singh, M. and Das, R.P. (2011). Zinc for the common cold. Cochrane Database Syst. Rev. 2:CD001364 (Pub Med abstract).

Vallee, B.L. and Falchuk, K.H. (1993). The biochemical basis of zinc physicology. Physiol. Rev. 73: 79-118.

Van Wovwe, J.P. (1989). Clinical and laboratory diagnosis of acrodemattittis enteropathica. Eur. J. Pediatr., 2: 149 